\title{
Johanna Wyn, Helen Cahill, Dan Woodman, Hernán Cuervo, Carmen Leccardi and Jenny Chesters: Youth and the New Adulthood: Generations of Change
}

162 pages, Springer, 2020. ISBN 978-981-15-3364-8 (hb)

\author{
Howard Williamson ${ }^{1}$ \\ Published online: 1 September 2020 \\ (C) Springer Nature Singapore Pte Ltd. 2020
}

This book is a rare treat, given the volume of too often obtuse material that is churned out on young people's lives. Moreover, it is rare for many different though related reasons. It is, exceptionally, both scholarly and readable, advancing theoretical contentions firmly anchored within robust empirical data. As young people throughout the world have confronted and experienced an expansion of further and higher education (and an expectation that they should participate in it) while anticipating and having to adjust to increasingly precarious employment prospects and working conditions, this study from Australia (drawing from the Life Patterns research program) reflects on the life course of two cohorts on young people, those who were late teenagers in the 1990s and, 15 years later, in the 2000s. The study is methodologically innovative, starting conventionally with a mix of surveys and interviews but more recently adding 'dialogic workshops' to enable the cross-fertilisation of data collection and thereby dramatically enriching the ensuing analysis, injecting - as the editors put it - 'new life to old dynamics' (p.3) and emphasising the criticality of relationships and interaction across different spheres of life, over time. This is something I have argued for throughout my academic life, to rid ourselves of the self-indulgent and static analysis of single-issue concepts such as 'generation' or 'resilience' that rarely moves beyond the realms of the academic seminar and instead to consider them in the round, as young people endeavour to make sense of their lives and themselves in increasingly uncertain and challenging times. That takes the debate to another level of theory and analysis and then further, even though it heightens the complexity of drawing practical implications, into the sphere of policy and practice. It is worth noting that the book's focus on a (though it emphasises 'the') 'new adulthood', was published just before the COVID-19 crisis hit the world!

In that respect, it could hardly have been more prophetic. The 'zeitgeist' of these cohorts of young people/young adults is the mismatch between past expectations,

Howard Williamson

howard.williamson@southwales.ac.uk

1 University of South Wales, Pontypridd, UK 
present realities and unpredictable futures, 'producing feelings of anxiety and powerlessness, and a sense of being wronged by history' (p.7). Whether or not the book provides striking new insights, as it claims to do, is a matter for some debate, but it certainly brings some buried treasures of empirical evidence and considered argument to the surface and into the light. For that reason, it is an important contribution to contemporary youth studies, of significance for scholars and students alike, as well as providing those in youth policy and practice to re-think their approaches to strengthening life chances and the life course for young people.

There is strong, but arguably necessary, repetition across chapters of some key issues, notably the gender inequalities that worsen, as women find their pre-eminence in education in recent years sliding backwards as they move forward in the labour market and as they take primary responsibility for family life and child-rearing. There is also repeated emphasis on the fact that precarious employment is no longer an 'early career' experience for more and more young people but a continuing characteristic of working life for growing numbers of adults. There is less and less sense of eventually landing a secure and sustainable job. This produces an incapacity to plan and an idea of time that shrinks inexorably towards the present. [These arguments brought sharply to my mind my own knowledge of those in the always precarious illegal economy who have never looked too far back or too far forward: such a feeling of constrained and constricted time now appears to be increasingly afflicting those in legitimate work.] It also produces a greater attention to localism, better to stay attached to local space and place, for both pragmatic material and more inter-personal psychological reasons.

Though many of the arguments should not really take us too much by surprise, the insight they offer through the rich data at the disposal of this research team has certainly strengthened their profile in relation to the more atomised positions and perspectives taken too often in youth studies - whether at similar points within the life course, where too much has been segmented and as a result fragmented, or over time along the life course. Familiar themes, such as generations, inequalities, temporality and the impact of social and economic conditions, are subjected to more nuanced consideration and, as a result, new approaches to understanding these most recent generations of change. In particular, new light is shed on how these two cohorts of young people have navigated and are navigating, circumstances over which they have little control and are facing a future for which there is no blueprint and which is always present, yet invisible. Transitions do not stop, they evolve and they are embedded within, and connected across, many different life domains. At last we have a book that not only grasps this point but illustrates it powerfully through the empirical data at its disposal.

The book would, however, have benefited from a bit more proof reading and editing. The generally beautifully written text is often spoilt by the surprising number of words absent from key sentences, confusing the reader and spoiling the argument. The editors do acknowledge some repetition between the 'stand-alone' chapters, but there is also too much unnecessary repetition — of arguments and terminology — within the chapters. The chapters are already short and sharp and commendably to the point, but more theoretical consideration and empirical illustration might have been presented in lieu of some too often repeated assertions.

In sum, which always a risky challenge given the heterogeneity of pathways into adulthood taken even from relatively homogeneous origins (the point I have made forcefully in my 47-year 'longitudinal ethnography' of the Milltown Boys, 
who came from a shared background of abject social deprivation), the book confirms the similar hopes and expectations that prevail amongst young people-basically what has counted as a good life in the past: a relationship, home ownership, a family and secure and meaningful work-but points to how the economic conditions and social structures that supported such possibilities in the post-war period have now declined, even decayed. It now takes very different resources and connections to achieve them, including a different set of subjectivities and aspirations and human and financial support beyond the labour market. This is what has shaped the new adulthood, and young people unable to engage with it through their own resilience and unable to access opportunities emanating from those other sources are destined to struggle. Without quite dramatic public policy evolution and transformation, which is now less likely than it ever was on account of the huge debts accumulating through dealing with COVID-19, many more young people will face the prospect of falling short of their desired destinations.

And yet - as I read successive chapters about, for example, the forging and shaping of the 'entrepreneurial self' and the resurrection of the importance of the family as a safety net ('a shelter from the uncertainty endemic to contemporary life'(p.124))-I could not help wondering whether this really is a 'new' adulthood or simply a return to the kind of adulthood that has largely prevailed throughout most of the world for most of the time. Perhaps the 'old' adulthood - the referential point for this analysis - was the good fortune of a small cohort of post-war baby boomers living in contexts of buoyant economies and emergent welfare states. For them, that was the window for secure employment, decent wages, free health care, social housing and the possibility of owner occupation. For sure, there are now new uncertainties and anxieties such as climate change and global terrorism, but arguably precarity and insecurity have simply returned to those societies, albeit cushioned for some by the fortunate circumstances and accumulated resources of their parents. For many young people across the world, perhaps it never went away. And as western societies dismantle the last vestiges of their welfare states and embrace populist authority, a more virulent 'new' adulthood is likely to be here to stay, particularly for those without the connections and support outlined in this book, whatever the authors may suggest: 'Ultimately, old and new patterns of inequalities require new policy approaches to make sure that all young people can achieve their aspirations, live well, and contribute to society' (p.112). Elsewhere in the book, however, respondents to the study reveal little confidence in governments to take appropriate action on matters of concern to them, whether the environment, jobs or the affordability of housing (Chapter 9).

I am not sure whether we should express a wry smile or cry, but employment for these young people, given its precarious character, is at one stage in the book implicitly likened to a virus, in that it has 'the capacity to infect every space of an individual's life, for which families are increasingly important to provide the antidote to avoid translating precarious work into precarious lives' (p.24). Little did the writers of this book know that young people entering the 'new adulthood' will now (a third generation after the two who are reported on for this analysis), following the real virus of the global coronavirus pandemic, have to work out how to navigate the 'new normal', too. Indeed, as I have suggested, another yet more virulent version of this 'new' adulthood may not be far over the horizon. 